\title{
FABRICANDO CONSENSO NO BRASIL: A MÍDIA E A EXCLUSÃO DE CANDIDATOS NAS ELEIÇÕES BRASILEIRA E VENEZUELANA DE 2018
}

\section{MANUFACTURING CONSENT IN BRAZIL: THE MEDIAAND THE EXCLUSION OF CANDIDATES IN THE 2018 BRAZILIAN AND VENEZUELAN ELECTIONS}

\author{
Rafael Sabatini Oliveira Lalli ${ }^{1}$ \\ Vânia Braz Oliveira²
}

Resumo: Neste artigo, foi aplicado o "modelo de propaganda" de Chomsky \& Herman no exame da cobertura feita pelas mídias de massa brasileiras sobre a exclusão de candidatos por processos jurídicos das eleições presidenciais brasileira e venezuelana de 2018. Para tal, foi empregada a metodologia chomskyana de estudo comparativo do material produzido pelo jornal O Estado de São Paulo entre $1^{\circ}$ de janeiro e 31 de maio de 2018 sobre os candidatos excluídos de cada pleito. Foram analisados o enquadramento da questão praticado pelo jornal em cada caso por meio de técnicas de representação, a pluralidade de opiniões apresentadas sobre o assunto e o posicionamento dos autores do material opinativo do veículo. Observou-se que a cobertura do jornal corrobora acusações de ataques à liberdade de candidatura no caso da eleição venezuelana, enquanto rechaça tais alegações no caso da eleição brasileira.

Palavras-chave: Jornalismo. Propaganda. Mídia. Brasil. Venezuela.

Abstract: In this article, Chomsky \& Herman's "propaganda model" was applied on the examination of the news coverage practiced by Brazilian mass media regarding the exclusion of candidates due to legal processes in the 2018 Brazilian and Venezuelan presidential elections. To this end, this research employs the chomskyan methodology of conducting a comparative study of the news content concerning the excluded candidates from each election produced by Brazilian newspaper O Estado de São Paulo between January 1st and May 31st of 2018. The analysis focused on: how the paper framed the matter in each case through representation techniques, the plurality of opinions presented, and how authors of opinion pieces positioned themselves. The results show that the newspaper's coverage corroborates claims of attacks on the freedom of candidacy in the Venezuelan election, whilst rejecting such claims in the Brazilian election.

Key words: Journalism. Propaganda. Media. Brazil. Venezuela.

Data de submissão: 19.04.2021

Data de aprovação: 02.07.2021

Identificação e disponibilidade:

(https://revista.univap.br/index.php/revistaunivap/article/view/2608, http://dx.doi.org/10.18066/revistaunivap.v27i54.2608).

\footnotetext{
${ }^{1}$ Faculdade de Ciências Sociais Aplicadas e Comunicação (FCSAC), Universidade do Vale do Paraíba - Univap, E-mail: raffa.lalli@yahoo.com.br.

${ }^{2}$ Faculdade de Ciências Sociais Aplicadas e Comunicação (FCSAC), Universidade do Vale do Paraíba - Univap, E-mail: vaniajor@univap.br.
} 


\section{INTRODUÇÃO}

Em 1988, Noam Chomsky e Edward S. Herman lançaram o livro Manufacturing Consent: The political economy of the Mass Media ("Fabricando Consenso: A política econômica das Mídias de Massa", em tradução livre), no qual propõem um "modelo de propaganda" (MP daqui em diante) para analisar a cobertura noticiosa praticada pelas mídias de massa. Embora não aleguem que a função propagandística seja a única exercida por essas mídias, os autores afirmam que as escolhas, ênfases e omissões praticadas por elas podem ser melhor compreendidas quando analisadas nesses termos (CHOMSKY; HERMAN, 2002, p. LIX).

Propaganda, segundo a definição de Harold Lasswell (1927), é "o manejo de atitudes coletivas pela manipulação de símbolos significativos" (LASSWELL, 1927, p. 627 , tradução nossa ${ }^{3}$ ). Em outras palavras, fazer propaganda é "apresentar um objeto em uma cultura de maneira a organizar certas atitudes culturais em relação a ele" (ibid, p. 629, tradução nossa ${ }^{4}$. Como, então, as mídias de massa fariam isso?

Walter Lippmann (1922) nota que o mundo real com o qual precisamos lidar é externo a nós: está fora do nosso alcance, da nossa mente, e por isso precisa ser explorado, reportado e imaginado (LIPPMANN, 2020, p. 20). Ou seja, é preciso criar uma representação dele, e é essa representação que estará ao nosso alcance - é em função dela que agiremos sobre o mundo real (LIPPMANN, 2020, p. 13).

Contudo, Stuart Hall (1997) mostra que o processo de representação é, em si, um processo de criação de significados. Ao examinar a forma como eventos são representados pelas mídias, ele indica que:

O que se pode dizer acerca desses eventos é que não há apenas um
significado verdadeiro fixo sobre eles. [...] A representação não captura
realmente o processo em absoluto, porque não havia nele absolutamente
nada fixo de início para ser representado. [...] Não que nada esteja
acontecendo no mundo, mas o que é duvidoso é qual é o verdadeiro
significado do evento, e o verdadeiro significado dele irá depender de que
significado as pessoas enxergarão nele; e os significados que as pessoas
enxergarão dependem de como ele foi representado (HALL, 1997, p. 7 ,
tradução nossa ${ }^{5}$ )

Pierre Bourdieu (1989) indica que há nas relações de comunicação uma disputa pelo "poder simbólico", na qual "as diferentes classes e fracções de classes estão numa luta propriamente simbólica para imporem a definição do mundo social mais conforme aos seus interesses" (BOURDIEU, 1989, p. 11). Nessa mesma linha, Hall afirma que "a questão da circulação de significados quase imediatamente envolve a questão de poder" (HALL, 1997, p. 14, tradução nossa6). Perceber essa correlação entre representação e poder necessariamente suscita as perguntas: quem detém esse poder, por quais canais ele é exercido, a fim de circular quais significados para quem? Para fazer propaganda, é preciso ter o máximo de controle possível sobre os canais

\footnotetext{
${ }^{3}$ Propaganda is the management of collective attitudes by the manipulation of significant symbols.

${ }^{4}$ The presentation of an object in a culture in such a manner that certain cultural attitudes will be organized toward it.

5 The one thing you can say about those events is that there is no one true, fixed meaning about it. [...] Representation doesn't really capture the process at all, because there was nothing absolutely fixed there in the first place to represent [...] Not that nothing is happening in the world, but what is dubious is what is the true meaning of it, and the true meaning of it will depend on what meaning people make of it; and the meanings that they make of it depends on how it is represented.

${ }^{6}[\ldots]$ The question of the circulation of meaning almost immediately involves the question of power.
} 
de representação, a fim de "multiplicar todas as sugestões favoráveis às atitudes que se deseja produzir e fortalecer, e para restringir todas as sugestões que são desfavoráveis a elas" (LASSWELL, 1927, p. 630, tradução nossa7).

Existem muitas formas de circular significados em uma sociedade e assim, embora as mídias de massa não sejam o único canal para tal, elas sem dúvida são um dos sistemas mais poderosos e extensos pelos quais se pode fazê-lo (HALL, 1997, p. 14). O que o MP propõe é que, em sociedades capitalistas, o controle dessas mídias está concentrado nas mãos das classes dominantes (CHOMSKY; HERMAN, 2002, p. 2), refletindo um cenário mais amplo de concentração de riqueza. Como resultado, elas agiriam em conformidade com as narrativas dessas elites, buscando "obter a concordância do povo a respeito de assuntos sobre os quais ele não estava de acordo por meio das novas técnicas de propaganda política" (CHOMSKY, 2013, p. 14-15).

Diferente do que acontece em sociedades regidas por estados totalitários - onde a ligação entre as elites governamentais e as mídias é mais evidente -, as mídias em sociedades liberais capitalistas são de propriedade privada e operam com base nas leis do livre-mercado, sendo supostamente mais democráticas. O que o MP propõe, entretanto, é que os "processos de mercado naturalmente restringem a liberdade de expressão e marginalizam o dissenso" (HERMAN, 1997, p. 168, tradução nossa ${ }^{8}$ ). Isso ocorre através da atuação de cinco filtros pelos quais o material noticioso produzido pelas mídias de massa precisa passar antes de ser publicado. Os filtros propostos pelo MP são:

(1) o tamanho e concentração de propriedade, a riqueza dos proprietários e a orientação para o lucro das companhias midiáticas dominantes; (2) a publicidade como fonte de renda primária das mídias de massa; (3) a confiança das mídias em informações fornecidas pelo governo, pelo empresariado e por "experts" patrocinados e aprovados por essas fontes primárias e agentes do poder; (4) o "flak", ou "crítica intensa", como um meio de disciplinar a imprensa; e (5) o "anticomunismo" como religião nacional e mecanismo de controle. (CHOMSKY; HERMAN, 2002, p. 2, tradução nossa ${ }^{9}$ )

Ao agirem interativamente, esses filtros fixam as premissas do discurso e da interpretação, definindo o que é e o que não é noticiável. O viés na cobertura noticiosa advém da pré-seleção de pessoas que internalizaram as preconcepções desse sistema e se adaptaram às limitações impostas pelas estruturas de poder proprietário, organizacional, mercadológico e político, com jornalistas promovendo a autocensura para se ajustar aos requerimentos midiáticos (CHOMSKY; HERMAN, 2002, p. LX), num processo que ocorre com aparente naturalidade.

Embora o MP tenha sido inicialmente idealizado para analisar o comportamento das mídias de massa estadunidenses, a sua aplicabilidade em outros países é evidente: ao longo dos anos, o modelo foi empregado no estudo da cobertura midiática praticada em lugares bastante diversos, como Holanda, Canadá, Reino Unido, Índia e Quênia (MACLEOD, 2019, p. 7). Alan Macleod (2019) nota algumas razões para

\footnotetext{
7 The problem of the propagandist is to multiply all the suggestions favorable to the attitudes which he wishes to produce and strengthen, and to restrict all suggestions which are unfavorable to them.

${ }^{8}$ A free market model [...] shows how market processes naturally constrain free expression and marginalize dissent.

${ }^{9}(1)$ The size, concentrated ownership, owner wealth, and profit orientation of the dominant mass-media firms; (2) advertising as the primary income source of the mass media; (3) the reliance of the media on information provided by government, business and "experts" funded and approved by these primary sources and agents of power; (4) "flak" as a means of disciplining the media; and (5) "anticommunism" as a national religion and control mechanism.
} 
essa facilidade de generalização:

A concentração de propriedade das mídias ao redor do mundo espelha os Estados Unidos, enquanto a dependência delas de publicidade corporativa para gerar receita e de fontes oficiais para obter informação e dados fazem o MP extremamente relevante para o resto do mundo. Ademais, a internacionalização das mídias devido à Internet e ao avanço global de uma lógica econômica neoliberal de mercado significa que ao redor do mundo as mídias estão cada vez mais se parecendo com, e operando sob as mesmas restrições que, as mídias americanas (MACLEOD, 2019, p.7, tradução nossa ${ }^{10}$ )

Esta pesquisa tem, portanto, o intuito de aplicar o MP no estudo da cobertura noticiosa praticada pelas mídias de massa brasileiras. Para tal, propomos um estudo de caso comparativo, analisando paralelamente o material produzido por uma dessas mídias sobre a exclusão de candidatos em função de processos jurídicos nas eleições presidenciais de 2018 ocorridas no Brasil e na Venezuela.

Tal método de estudo comparativo tem respaldo na literatura do MP: o terceiro capítulo de Manufacturing Consent é inteiramente dedicado à análise da cobertura de eleições em países de terceiro mundo. Nele, os autores afirmam que, ao cobrirem tais eventos, as mídias de massa norte-americanas seguem um padrão dicotomizante que acompanha a política internacional dos Estados Unidos: eleições realizadas em países aliados e submissos aos interesses americanos são vistas como legítimas, enquanto aquelas realizadas em países inimigos são tratadas como artimanhas insignificantes empregadas para validar o sistema político do regime no poder (CHOMSKY; HERMAN, 2002, p. 87).

A "liberdade de formar partidos políticos, organizar seus membros, apresentar candidatos e fazer campanha sem medo de extrema violência" é um dos "parâmetros básicos que tornam uma eleição significativa ou insignificante em antecedência aos procedimentos do dia da votação" (CHOMSKY; HERMAN, 2002, p. 89, tradução nossa $\left.{ }^{11}\right)$. Portanto, em países nos quais tal liberdade - e, especificamente neste caso, a liberdade de apresentar candidatos (ou, como nos referiremos a ela, a "liberdade de candidatura") - esteve em questão, é relevante entender como ela foi representada pelas mídias de massa.

O pleito venezuelano de 2018, vencido pelo incumbente Nicolás Maduro, se deu em meio a uma grave crise política e econômica. Inúmeros políticos opositores foram impedidos de concorrer devido a condenações judiciais prévias por diversos motivos, de corrupção a "violência e desestabilização" (ESTADÃO, 2018). A oposição local, os EUA e a União Europeia acusaram o processo de fraude e denunciaram a exclusão de candidatos oposicionistas por configurar desrespeito ao pluralismo político (CONSELHO DA UE, 2018). O Brasil, como membro do Grupo de Lima, não reconheceu o resultado das eleições venezuelanas (BRASIL. MINISTÉRIO DAS RELAÇÕES EXTERIORES, 2019).

O pleito brasileiro, por sua vez, também se deu num contexto de crise política e

\footnotetext{
${ }^{10}$ Concentrated media ownership around the world mirrors the United States, while the dependence on corporate advertising for revenue and on official sources for information and data make the propaganda model highly relevant to the rest of the world. Furthermore, the internationalization of media due to the Internet and the worldwide advance of neoliberal free-market economics mean media around the world is increasingly resembling and operating under the same constraints of American media.

11 The basic parameters that make an election meaningful or meaningless prior to the election-day proceedings (...) include: (...) (4) freedom to form political parties, organize members, put forward candidates, and campaign without fear of extreme violence.
} 
econômica. Vencido por Jair Bolsonaro, o processo foi marcado pela exclusão de Luiz Inácio Lula da Silva, favorito nas pesquisas pré-eleitorais (IBOPE, 2018), em função de uma condenação judicial. A oposição local considerou a exclusão do petista "parcial e discriminatória" e "uma violência judicial" (PT, 2018).

Pelo MP, esperaríamos que as mídias brasileiras fossem críticas à exclusão de opositores na eleição venezuelana, considerando os processos jurídicos contra eles como ataques à liberdade de candidatura. Ao mesmo tempo, preveríamos que elas não retratassem eventos similares nas eleições brasileiras como ataques à liberdade de candidatura, julgando a exclusão de opositores justa e limpa, e ignorando, minimizando ou rechaçando alegações em contrário. Nesta pesquisa, pretendemos testar a validade dessas proposições.

\section{COMUNICAÇÃO, REDES DIGITAIS SOCIAIS DIGITAIS E HUMANIZAÇÃO}

O método chomskyano de análise da cobertura midiática de eleições baseia-se no estudo de caso comparativo entre o material produzido por mídias de massa acerca de pleitos ocorridos em países com condições políticas e sociais similares (MACLEOD, 2018, p. 140-141). Consideramos que essa premissa de similaridade pode ser suficientemente verificada no caso de Brasil e Venezuela: dois países sul americanos com um longo histórico de desigualdades sociais que entraram em seus processos eleitorais no ano de 2018 em meio a crises políticas decorrentes, em grande medida, da recessão econômica que se abateu sobre a região com o fim do boom de commodities (CORSI; SANTOS; CAMARGO, 2019).

Esse tipo de estudo costuma ser empregado na análise da cobertura praticada por determinadas mídias sobre duas eleições ocorridas no estrangeiro (MACLEOD, 2018), e também já foi usado para analisar a cobertura dada a dois candidatos dentro de uma eleição doméstica (MAWEU apud MACLEOD, 2019). Nesta pesquisa, pretendemos comparar a cobertura de uma eleição doméstica e outra estrangeira.

Para o estudo comparativo que propomos, não seria adequado utilizar a ferramenta chomskyana de comparação do total de matérias sobre um e outro pleito, já que a cobertura doméstica naturalmente tenderia a ser maior. Porém, ainda é possível comparar a frequência de determinados assuntos dentro de cada cobertura, além da forma como tais assuntos foram abordados. Assim, observamos a quantidade de matérias que falam de três temas ao mencionar os candidatos excluídos de cada pleito: (1) as eleições em si; (2) os processos jurídicos contra os candidatos; e (3) a temática de ataque à liberdade de candidatura. Em seguida, concentramos nossa análise nas matérias que falam sobre as eleições em si a fim de examinar a pluralidade de opiniões expressas sobre a exclusão dos candidatos nesse contexto. Também averiguamos a autoria dessas matérias e o posicionamento expresso pelos autores do material opinativo do jornal (artigos de opinião e editoriais) sobre a questão. Todos esses dados foram analisados em busca de evidências da atuação dos filtros do MP.

A fim de garantir que seria coletado o máximo de notícias sobre o tema, foram definidas palavras-chave abrangentes como ponto de partida: "Venezuela" para o ambiente estrangeiro e "Lula" para o doméstico. O objetivo foi traçar um recorte daquelas matérias que mencionam os candidatos presidenciais excluídos de cada eleição. No caso venezuelano, propomos que, por se tratar de país estrangeiro, todos os candidatos excluídos do pleito seriam virtualmente sempre mencionados no contexto daquele país. Aplicada a palavra-chave, estabelecemos um recorte das matérias que mencionam os candidatos excluídos - nomeadamente Henrique Capriles, Leopoldo López, Antonio Ledezma e Freddy Guevara, além da coalizão 
opositora Mesa de la Unidad Democrática (MUD). Também foram incluídas no recorte as matérias que não os mencionam explicitamente, mas falam em "opositores", "candidatos" ou "políticos" em referência a eles. No ambiente doméstico, por sua vez, a escolha da palavra-chave "Lula" se deu pela compreensão de que seria a que tem correlação mais direta com o candidato excluído do pleito brasileiro.

Para a coleta de material noticioso, foi selecionada a "edição Brasil" do jornal O Estado de São Paulo. A escolha desse veículo se deu em razão da sua relevância no cenário midiático brasileiro. Ademais, o jornal contava à época dos eventos estudados com uma proporção relativamente grande de assinantes físicos - 1 assinante físico para cada 1,4 digital (HIROSE, 2020) -, o que significa que a sua versão impressa ainda tinha grande relevância para sua audiência, mesmo com a hegemonia do modelo digital. A coleta de dados ocorreu através do acervo digital do jornal: ou seja, a partir das suas versões impressas digitalizadas, e não do seu portal online de notícias.

Foi estabelecido um recorte temporal de cinco meses - entre $1^{\circ}$ de janeiro e 31 de maio de 2018 -, período no qual ocorreram eventos importantes em ambos pleitos, como: o fracasso das negociações entre governo e oposição para a eleição venezuelana (em janeiro), a eleição venezuelana em si (em maio), a condenação de Lula em segunda instância pelo Tribunal Regional Federal da Quarta Região (TRF4) (em janeiro), e a prisão do petista, decretada (em abril) por Sérgio Moro, à época juiz da Lava Jato.

Também foram realizadas uma pesquisa documental - a fim de levantar documentos oficiais e estudos referentes aos países selecionados e suas respectivas eleições - e uma pesquisa bibliográfica - com o intuito de expandir e atualizar as ferramentas do MP para o contexto informacional do século XXI. O objetivo foi munir o pesquisador com conhecimentos adicionais para aprimorar a análise dos dados.

\section{RESULTADOS}

A cobertura de candidatos presidenciais excluídos da eleição contou com um total de 66 matérias no caso da Venezuela e 1209 matérias no caso do Brasil. Esses números incluem as matérias que têm esses candidatos como tema central e também aquelas que os mencionam brevemente ao discorrer sobre outro assunto. A seguir, apresentamos esses dados (Quadros 1 a 6) nos recortes dos meses de janeiro (mês 01), fevereiro (mês 02), março (mês 03), abril (mês 04) e maio (mês 05) de 2018, e em todo o período do recorte temporal (Total).

No recorte da Venezuela (Quadro 1), do total de 66 matérias que mencionam os candidatos excluídos da eleição, 55 tratam da eleição presidencial (tratam das negociações para a realização da eleição, de pesquisas eleitorais, campanhas eleitorais, candidatos, explicam propostas governamentais ou falam do pleito em si); 19 tratam dos processos jurídicos contra os candidatos (condenações judiciais, prisões, processos movidos contra eles no 'Consejo Nacional Electoral' [CNE] - a justiça eleitoral venezuelana - e suas vidas na prisão ou no exílio); e 37 falam em ataque à liberdade de candidatura (tratam da exclusão dos candidatos como ataque à democracia, violação da pluralidade política, perseguição política, repressão a opositores, consideram os processos jurídicos "lawfare" - ou seja, perseguição política por meios jurídicos - ou usam termos como "fraude" e "farsa" para falar da eleição no contexto da exclusão de candidatos; não são computadas nesta categoria matérias que falam em "fraude", "farsa" ou "perseguição" de maneira inespecífica ou exclusivamente jurídica). Vale ressaltar que a categoria "mencionam os candidatos 
excluídos" equivale ao total de matérias analisadas no recorte. Contudo, seu valor não é uma soma exata das outras categorias, pois há matérias que falam simultaneamente de mais de uma das temáticas recortadas para análise.

Quadro 1 - Total de matérias que mencionam os candidatos excluídos do pleito na Venezuela ${ }^{12}$

\begin{tabular}{|c|c|c|c|c|c|c|}
\hline TEMÁTICA & $\begin{array}{c}\text { Mês } \\
\mathbf{0 1}\end{array}$ & $\begin{array}{c}\text { Mês } \\
\mathbf{0 2}\end{array}$ & $\begin{array}{c}\text { Mês } \\
\mathbf{0 3}\end{array}$ & $\begin{array}{c}\text { Mês } \\
\mathbf{0 4}\end{array}$ & $\begin{array}{c}\text { Mês } \\
\mathbf{0 5}\end{array}$ & Total \\
\hline Mencionam os candidatos excluídos & 18 & 19 & 6 & 4 & 19 & 66 \\
\hline Falam da eleição presidencial de 2018 & 13 & 17 & 2 & 4 & 19 & 55 \\
\hline Falam dos processos contra candidatos & 5 & 10 & 0 & 0 & 4 & 19 \\
\hline Falam em ataque à liberdade de candidatura & 8 & 15 & 1 & 3 & 10 & 37 \\
\hline
\end{tabular}

Fonte: Elaborado pelos autores. Acervo Estadão (2018).

Em seguida, focamos nossa análise nas 55 matérias dentro do recorte que falam da eleição presidencial venezuelana de 2018. Nessa temática, observamos o total de matérias em que são apresentadas citações diretas a respeito da exclusão de candidatos (Quadro 2) expressas por: opositores - incluindo os próprios candidatos excluídos - (16); membros do governo venezuelano (10); representantes de países opositores ao governo (20); e por representantes de países aliados do governo (3). Vale ressaltar que essas categorias refletem o número de matérias em que esses opinadores são citados e, portanto, não são mutuamente excludentes.

Quadro 2 - Pluralidade de opiniões sobre "exclusão de candidatos" nas matérias que falam sobre a eleição presidencial venezuelana de $2018^{13}$

\begin{tabular}{|c|c|c|c|c|c|c|}
\hline MATÉRIAS QUE CITAM & $\begin{array}{c}\text { Mês } \\
01\end{array}$ & $\begin{array}{c}\text { Mês } \\
02\end{array}$ & $\begin{array}{c}\text { Mês } \\
03\end{array}$ & $\begin{array}{c}\text { Mês } \\
04\end{array}$ & $\begin{array}{c}\text { Mês } \\
05\end{array}$ & Total \\
\hline Opositores & 6 & 6 & 0 & 2 & 2 & 16 \\
\hline Governo & 2 & 3 & 0 & 0 & 5 & 10 \\
\hline Comunidade Internacional Anti-governo & 5 & 5 & 0 & 2 & 8 & 20 \\
\hline Comunidade Internacional Pró-governo & 0 & 1 & 0 & 0 & 2 & 3 \\
\hline
\end{tabular}

Fonte: Elaborado pelos autores. Acervo Estadão. (2018).

Em relação a autoria (Quadro 3), classificamos as 55 matérias que tratam da eleição presidencial venezuelana de 2018 com base em sua assinatura: matéria assinada por Agência Internacional de Notícias (23); matéria assinada por Correspondente nos EUA ou na UE (8); matéria assinada pelo enviado especial a Caracas e à Venezuela, Rodrigo Cavalheiro (7); matéria assinada por jornalista no Brasil (5); editorial - conhecido no jornal como "Notas e Informações" (4); artigo de opinião original do jornal (5); artigo de opinião traduzido de jornal americano ou

12 A categoria "mencionam os candidatos excluídos" representa o total de matérias analisadas neste recorte. Contudo, seu valor não equivale à soma das demais categorias pois elas não são mutuamente excludentes.

13 Os dados aqui apresentados dizem respeito às 55 matérias que "falam da eleição presidencial [venezuelana] de 2018" (ver Quadro 1). As categorias refletem o número de matérias que citam cada tipo de opinador e, portanto, não são mutuamente excludentes. 
europeu (5); e matéria sem assinatura explícita (3). Há matérias cuja assinatura se encaixa em mais de uma dessas categorias. Esses casos foram indicados nas notas de rodapé números 13 e 14 . Quanto ao posicionamento dos autores no material opinativo do jornal, notamos que todos os editoriais e artigos de opinião foram críticos ao governo ou à eleição, ou favoráveis ao posicionamento dos opositores.

Quadro 3 - Autoria das matérias que falam da eleição presidencial venezuelana de $2018^{14}$

\begin{tabular}{|c|c|c|c|c|c|c|}
\hline ASSINATURA & $\begin{array}{c}\text { Mês } \\
01\end{array}$ & $\begin{array}{c}\text { Mês } \\
02\end{array}$ & $\begin{array}{c}\text { Mês } \\
03\end{array}$ & $\begin{array}{l}\text { Mês } \\
04\end{array}$ & $\begin{array}{c}\text { Mês } \\
05\end{array}$ & Total \\
\hline Agência Internacional de Notícias & 10 & $7^{15}$ & 1 & 2 & 3 & 23 \\
\hline Correspondente nos EUA ou na UE & 0 & $4^{13}$ & 0 & 0 & $4^{16}$ & 8 \\
\hline Enviado especial a Caracas e à Venezuela & 0 & 0 & 0 & 0 & $7^{14}$ & 7 \\
\hline Jornalista no Brasil & 0 & $4^{13}$ & 0 & 0 & $1^{14}$ & 5 \\
\hline Editorial & 1 & 1 & 0 & 1 & 1 & 4 \\
\hline Artigo de opinião & 2 & 2 & $\mathbf{0}$ & 0 & 1 & 5 \\
\hline $\begin{array}{l}\text { Artigo de opinião traduzido de jornal dos EUA } \\
\text { ou da UE }\end{array}$ & 2 & 2 & $\mathbf{0}$ & $\mathbf{0}$ & 1 & 5 \\
\hline Matéria sem assinatura & 0 & 1 & 0 & 0 & 2 & 3 \\
\hline
\end{tabular}

Fonte: Elaborado pelos autores. Acervo Estadão (2018).

No recorte do Brasil (Quadro 4), das 1209 matérias que mencionam o candidato excluído da eleição, 538 falam da eleição presidencial (falam de pesquisas eleitorais, de candidatos presidenciais ou de suas propostas, fazem previsões eleitorais ou falam em "eleições" em referência à eleição presidencial; não foram computadas matérias que tratam em "democracia" de maneira ampla e inespecífica nem aquelas que falam somente das eleições legislativas ou dos executivos estaduais); 944 tratam dos processos contra o candidato (seus julgamentos, condenações e recursos a diversos tribunais, delações premiadas e depoimentos contra ele, sua possível exclusão da eleição pelo Tribunal Superior Eleitoral [TSE], sua prisão e vida no cárcere); e 80 abordam ataques à pluralidade política (idem à Venezuela). Houve instâncias em que a temática de ataques à liberdade de candidatura é negada ou respondida pelo autor da matéria ou pelo opinador citado. Esses casos foram indicados como "negam ou respondem" (entre parêntesis), como assinala a nota de rodapé número 16.

As categorias apresentadas no Quadro 4 não são mutuamente excludentes, pois há matérias que falam de mais de uma das temáticas recortadas para análise ao mencionar o candidato excluído.

\footnotetext{
14 Os dados aqui apresentados dizem respeito às 55 matérias que "falam da eleição presidencial [venezuelana] de 2018" (ver Quadro 1).

${ }^{15}$ A matéria "TPI analisará possíveis abusos do Chavismo" (09/02/18) é assinada pelo correspondente em Genebra, Jamil Chade, com colaboração da AFP. A matéria "Aliança opositora venezuelana decide não lançar candidato contra Maduro", com título na capa de "Oposição na Venezuela não terá candidato contra Maduro" (22/02/18), é assinada por AFP, EFE e Carla Araújo, jornalista em Brasília.

${ }^{16}$ A matéria "EUA ampliam sanções à Venezuela e bloco regional critica eleição de Maduro" (22/05/18) é assinada pela correspondente em Washington, Cláudia Trevisan, pelo enviado especial a Caracas, Rodrigo Cavalheiro, e pela jornalista em Brasília Lu Aiko Otta, com colaboração do correspondente em Genebra, Jamil Chade.
} 
Quadro 4 - Total de matérias que mencionam o candidato excluído do pleito no Brasil ${ }^{17}$

\begin{tabular}{|c|c|c|c|c|c|c|}
\hline TEMÁTICA & $\begin{array}{c}\text { Mês } \\
01\end{array}$ & $\begin{array}{c}\text { Mês } \\
02\end{array}$ & $\begin{array}{c}\text { Mês } \\
03\end{array}$ & $\begin{array}{c}\text { Mês } \\
04\end{array}$ & $\begin{array}{c}\text { Mês } \\
05\end{array}$ & Total \\
\hline Mencionam o candidato excluído & 307 & 160 & 229 & 366 & 147 & 1209 \\
\hline Falam da eleição presidencial de 2018 & 169 & 86 & 77 & 141 & 65 & 538 \\
\hline Falam dos processos contra o candidato & 257 & 115 & 155 & 308 & 109 & 944 \\
\hline $\begin{array}{c}\text { Falam em ataque à liberdade de candidatura } \\
\text { (Negam ou respondem) }\end{array}$ & $\begin{array}{c}29 \\
(17)\end{array}$ & $\begin{array}{c}10 \\
(6)\end{array}$ & $\begin{array}{c}8 \\
(3)\end{array}$ & $\begin{array}{c}\mathbf{2 9}(18) \\
(3)\end{array}$ & $\begin{array}{c}\mathbf{8} \\
(47)\end{array}$ \\
\hline
\end{tabular}

Fonte: Elaborado pelos autores. Acervo Estadão (2018).

Analisamos também o total de matérias em que são apresentadas citações diretas a respeito da exclusão do candidato dentro das 538 matérias do recorte que falam da eleição presidencial brasileira de 2018 (Quadro 5). Nesse contexto, foi observada a quantidade de matérias que citam "opiniões inimigas" (100) - ou seja, opiniões de opositores políticos ou de pessoas em geral que aprovam a exclusão do candidato da eleição (que concordam com sua condenação, prisão e exclusão do pleito, consideram os processos contra ele justos ou puramente técnicos, ou criticam a postura do candidato no contexto da sua exclusão do pleito); e aquelas que citam "opiniões aliadas" (125) - emitidas por seus aliados ou por pessoas em geral que reprovam sua exclusão, em sentido oposto ao descrito como opiniões inimigas. A categoria de opiniões aliadas inclui as opiniões do próprio candidato. Opiniões emitidas pelo autor da matéria não foram contabilizadas aqui. Contudo, ocorrem com frequência casos nos quais opiniões aliadas são respondidas pelo autor da matéria (39). Esses casos foram indicados como sendo "com resposta do autor" (entre parêntesis), como assinala a nota de rodapé número 17. Não houveram respostas sistemáticas a opiniões inimigas.

Também foram computadas matérias que falam da reação do "mercado" à exclusão do candidato do pleito (variações na taxa de câmbio ou na cotação da bolsa, "otimismo" ou "pessimismo" do mercado financeiro e previsões econômicas que levaram em conta a exclusão do candidato da eleição).

As categorias apresentadas no Quadro 5 refletem o número de matérias que citam cada tipo de opinador e, portanto, não são mutuamente excludentes.

17 A categoria "mencionam o candidato excluído" representa o total de matérias analisadas neste recorte. Contudo, seu valor não equivale à soma das demais categorias pois elas não são mutuamente excludentes.

${ }^{18}$ São indicadas entre parêntesis ("Negam ou respondem") aquelas matérias dessa categoria nas quais a temática de "Ataque à liberdade de candidatura" é mencionada a fim de ser negada ou respondida pelo autor ou opinador citado. 
Quadro 5 - Pluralidade de opiniões sobre "exclusão do candidato" nas matérias que falam sobre a eleição presidencial brasileira de $2018^{19}$

\begin{tabular}{|c|c|c|c|c|c|c|}
\hline MATÉRIAS QUE CITAM & $\begin{array}{c}\text { Mês } \\
01\end{array}$ & $\begin{array}{c}\text { Mês } \\
02\end{array}$ & $\begin{array}{c}\text { Mês } \\
03\end{array}$ & $\begin{array}{c}\text { Mês } \\
04\end{array}$ & $\begin{array}{c}\text { Mês } \\
05\end{array}$ & Total \\
\hline Opinião inimiga & 32 & 15 & 12 & 29 & 12 & 100 \\
\hline $\begin{array}{c}\text { Opinião aliada } \\
\text { (com resposta do autor) }\end{array}$ & $\begin{array}{c}40 \\
(11)\end{array}$ & $19(8)$ & $\begin{array}{c}16 \\
(6)\end{array}$ & $\begin{array}{c}35 \\
(10)\end{array}$ & $15(4)$ & $\begin{array}{c}125 \\
(39)\end{array}$ \\
\hline Reação do "mercado" & 26 & 5 & 6 & 18 & 6 & 61 \\
\hline
\end{tabular}

Fonte: Elaborado pelos autores. Acervo Estadão (2018).

Em relação a autoria (Quadro 6), classificamos as 538 matérias que tratam da eleição presidencial brasileira de 2018 com base em seu tipo: matéria comum (244); entrevista (44); coluna multitemática - como a "Coluna do Estadão" e a coluna "Direto da Fonte", de Sonia Racy - (45); tabela, infográfico ou linha do tempo (7); "Broadcast" econômico (5); "Repercussão" internacional (2); matérias de "Análise", "Cenário", "Para Lembrar", "Para entender" e derivados (20); editorial (44); e artigo de opinião (120).

O material opinativo do jornal - editoriais e artigos de opinião - também foi analisado em relação ao posicionamento expresso pelo autor, sendo categorizado como "contra", "neutro" ou "a favor" do candidato. As categorias "contra" e "a favor" foram estabelecidas com base nos critérios de posicionamento apresentados na análise de "pluralidade de opiniões", mas com foco exclusivo no posicionamento do autor do texto. Também foram considerados "contra" ou "a favor" aqueles textos em que houve posicionamento político explícito em relação ao candidato. Quando nenhum dos posicionamentos descritos foi observado, a favor ou contra, o artigo foi considerado neutro. Também foram considerados neutros os artigos que abordam o candidato marginalmente ao falar das eleições presidenciais brasileiras de 2018. Vale notar que os editoriais analisados foram agrupados no Quadro 6 em uma só categoria pois $100 \%$ deles foi considerado "contra" o candidato.

Quadro 6 - Tipos de matéria que falam sobre a eleição presidencial brasileira de $2018^{21}$

\begin{tabular}{|c|c|c|c|c|c|c|}
\hline ASSINATURA & $\begin{array}{c}\text { Mês } \\
\mathbf{0 1}\end{array}$ & $\begin{array}{c}\text { Mês } \\
\mathbf{0 2}\end{array}$ & $\begin{array}{c}\text { Mês } \\
\mathbf{0 3}\end{array}$ & $\begin{array}{c}\text { Mês } \\
\mathbf{0 4}\end{array}$ & $\begin{array}{c}\text { Mês } \\
\mathbf{0 5}\end{array}$ & Total \\
\hline Matéria Comum & 78 & 36 & 35 & 65 & 30 & 244 \\
\hline Entrevista & 16 & 8 & 4 & 10 & 6 & 44 \\
\hline Coluna Multitemática & 11 & 4 & 6 & 19 & 5 & 45 \\
\hline Tabela, infográfico ou linha do tempo & 2 & 0 & 1 & 2 & 2 & 7 \\
\hline "Broadcast" econômico & 3 & 0 & 1 & 1 & 0 & 5 \\
\hline
\end{tabular}

19 Os dados aqui apresentados dizem respeito às 538 matérias que "falam da eleição presidencial [brasileira] de 2018" (ver Quadro 4). As categorias refletem o número de matérias que citam cada tipo de opinador e, portanto, não são mutuamente excludentes.

${ }^{20}$ São indicadas entre parêntesis ("com resposta do autor") aquelas matérias nas quais opiniões aliadas são citadas a fim de serem respondidas pelo autor da matéria.

${ }^{21}$ Os dados aqui apresentados dizem respeito às 538 matérias que "falam da eleição presidencial [brasileira] de 2018" (ver Quadro 4). 


\begin{tabular}{|c|c|c|c|c|c|c|}
\hline "Repercussão" internacional & 1 & 0 & 0 & 1 & 0 & 2 \\
\hline Análise/Cenário/Para Lembrar/Para entender & 8 & 6 & 1 & 3 & 2 & 20 \\
\hline Editorial & 12 & 8 & 8 & 10 & 6 & 44 \\
\hline Artigo de opinião contra o candidato & 28 & 18 & 12 & 21 & 10 & 83 \\
\hline Artigo de opinião neutro & 10 & 6 & 8 & 8 & 4 & 36 \\
\hline Artigo de opinião a favor do candidato & 0 & 0 & 1 & 0 & 0 & 1 \\
\hline
\end{tabular}

Fonte: Elaborado pelos autores. Acervo Estadão (2018).

Um dado extra pertinente na cobertura da eleição brasileira foi o posicionamento da audiência do jornal em relação ao candidato excluído do pleito, expresso no "Fórum dos Leitores". Encontramos um total de 467 comentários que o mencionam, dos quais $451(96 \%)$ se posicionaram contra ele e $16(4 \%)$ a favor dele.

\section{DISCUSSÃO}

Na cobertura da Venezuela, dentre as matérias que mencionam os candidatos excluídos do pleito, $28,7 \%$ tratam dos processos jurídicos contra esses candidatos, enquanto $56 \%$ falam em ataque à liberdade de candidatura. Isso significa que, com frequência, alegações de ataque à liberdade de candidatura são feitas sem que os processos contra os candidatos sejam sequer mencionados.

Sobre isso, Francisco Sierra Caballero (2018) diz que, desde a ascensão do chavismo, a cobertura internacional da Venezuela tem sido marcada por uma série de "técnicas" que mergulharam o país no que ele chama de "cerco midiático" e "guerra de propaganda" (SIERRA CABALLERO, 2018, p. 239, tradução nossa ${ }^{22}$ ). Uma das técnicas notadas por Sierra Caballero é o uso de "campanhas contra a falta de liberdade de expressão e democracia" (ibid, p. 240, tradução nossa ${ }^{23}$ ), pelas quais o governo venezuelano é retratado como "ditatorial". O fenômeno de alegações frequentes de ataque à liberdade de candidatura sem menção aos processos jurídicos condiz com tal técnica. Afinal, uma representação que considera tais ataques mais relevantes do que os processos que em teoria os embasam induz a uma leitura de que esses ataques são um a priori da eleição venezuelana.

Além disso, as alegações de ataque à liberdade de candidatura receberam respaldo do jornal, aparecendo não só nas opiniões mais frequentemente citadas de opositores domésticos e internacionais ao governo venezuelano, como também no posicionamento dos autores de material opinativo. Isso pode ser observado na cobertura do dia 22 de maio, quando tais alegações aparecem nas falas da oposição internacional - em "EUA ampliam sanções à Venezuela e bloco regional critica eleição de Maduro" (Cláudia Trevisan, Rodrigo Cavalheiro e Lu Aiko Otta com colaboração de Jamil Chade), (TREVISAN; CAVALHEIRO; OTA, 2018) - e no posicionamento dos autores de "Injustas e ilegítimas" (CANTANHÊDE, 2018a) e "Simulacro de democracia" (editorial); (SIMULACRO..., 2018).

Por sua vez, opiniões do governo e seus aliados não só são menos citadas, como muitas vezes soam anacrônicas no contexto representado. A matéria "Chavismo

\footnotetext{
${ }^{22}$ Several techniques have been employed to step up the media siege and propaganda war in which the country is currently immersed.

${ }^{23}$ Campaigns against the lack of freedom of expression and democracy.
} 
antecipa para abril as eleições presidenciais na Venezuela" (AFP, EFE e Reuters, 24/01/18), (CHAVISMO..., 2018), por exemplo, diz que "analistas e opositores advertiam que o governo provavelmente adiantaria o processo para aproveitar a crise de credibilidade e as divisões internas" da MUD. Em seguida, Maduro é citado anunciando sua candidatura: "sou um humilde trabalhador, um humilde homem do povo". Tal fenômeno também é mencionado por Sierra Caballero (2018) como uma das técnicas de cobertura internacional da Venezuela, pela qual

\begin{abstract}
a mídia convencional internacional só cita fontes que refletem a posição dos EUA e de seus aliados oposicionistas, sem dar voz ao governo venezuelano, exceto com o fim de reforçar a priori o viés da cobertura noticiosa ou para ridicularizar os seus representantes de maneira conspícua (SIERRA CABALLERO, 2018, p. 240, tradução nossa ${ }^{24}$ )
\end{abstract}

$\mathrm{Na}$ cobertura do Brasil, dentre as matérias que mencionam o candidato excluído do pleito, $44 \%$ falam da eleição presidencial, enquanto $78 \%$ falam dos processos jurídicos contra o candidato. Isso significa que foi dada ampla ênfase aos processos jurídicos contra o candidato, em detrimento da sua participação na corrida eleitoral.

Mesmo nas matérias que tratam sobre a eleição presidencial, o jornal representou os processos contra o candidato como sendo estritamente "técnicos", sistematicamente rechaçando alegações de que eles teriam natureza política. $\mathrm{Na}$ análise "Julgamento técnico enfraquece tese do PT" (MAGALHÃES, 2018a), a autora afirma que "o julgamento estritamente técnico feito pela $8^{a}$ Turma do TRF-4 ontem enfraquece em muito a tese que o PT não se cansa de alardear de que o ex-presidente Lula é alvo de uma perseguição política", acrescentando que "diante do consistente arrazoado jurídico erigido em Porto Alegre, resta diminuído o mimimi petista de que Lula é vítima de perseguição".

Tais alegações de "vitimismo" são constantes na cobertura do jornal. De fato, o fenômeno representativo pelo qual o jornal "explica" eventos de forma a potencializar uma determinada leitura sobre eles é frequente. A matéria "PT teme encolher se Lula for barrado na eleição" (ROSA, 2018), por exemplo, afirma que "a ideia do partido é criar um clima de comoção no País durante a campanha e investir no discurso de 'nós contra eles', na tentativa de mostrar que Lula é 'vítima' de perseguição montada para impedi-lo de chegar à Presidência". Essa representação induz a uma leitura dos processos jurídicos como um contexto factual neutro e a reação do candidato e de seus aliados como politização.

Para além desses fenômenos, há também a questão da cobertura da temática de ataque à liberdade de candidatura em si, abordada em apenas $6 \%$ das matérias que mencionam o candidato. Ademais, muitas das menções à temática são feitas em contextos nos quais ela é negada pelo autor da matéria ou pelo opinador citado (cerca de $59 \%$ dos casos), como no artigo de opinião "Que as instituições falem" (MAGALHÃES, 2018b), em que a autora questiona: "Preso político? Onde? Em que mundo vive quem repete tal estultice?"; e na chamada de capa para uma entrevista do ex-presidente Fernando Henrique Cardoso, em que é ressaltada a fala do tucano: “"Lula não é preso político, é político preso"” (HOLANDA; KATTAH, 2018).

Quanto à pluralidade de opiniões sobre a exclusão do candidato no contexto das eleições presidenciais, há mais opiniões aliadas (125) do que opiniões inimigas (100).

${ }^{24}$ The mainstream international media only cite sources reflecting the stance of the USA and its opposition allies, without giving voice to the Venezuelan government, except to reinforce a priori the bias in news coverage or to ridicule its representatives in a conspicuous fashion. 
Contudo, $31 \%$ das citações a opiniões aliadas ocorrem no material opinativo do jornal, em circunstâncias nas quais são respondidas pelo autor da matéria. De fato, a maior presença dessas opiniões está diretamente relacionada a esse fenômeno, visto que ao se considerar apenas as matérias em que opiniões aliadas não são respondidas (86) elas se tornam minoria em relação às opiniões inimigas.

Mesmo assim, poderia ser alegado que a margem de diferença entre o número de opiniões de cada lado é tênue, ou que há um grande número de citações a opiniões aliadas, o que caracterizaria uma cobertura equilibrada. Porém, o contexto em que tais opiniões aparecem é de suma importância:

\begin{abstract}
Que as mídias providenciem alguns fatos sobre um assunto, contudo, não prova absolutamente nada sobre a adequabilidade de tal cobertura. De fato, as mídias de massa literalmente suprimem uma grande quantidade de informações, (...) mas ainda mais importante nesse contexto é a questão da atenção dada a um fato - sua localização, seu tom, suas repetições, a estrutura de análise na qual ele é apresentado e os fatos relacionados que o acompanham e significam (ou impedem sua compreensão) (CHOMSKY; HERMAN, 2002, p. LXII-LXIII, tradução nossa ${ }^{25}$ )
\end{abstract}

Notamos que opiniões aliadas costumam ser expressas em dois contextos mais comuns. O primeiro é o de autocrítica partidária, em que as falas de mais destaque na matéria são aquelas que afirmam que a esquerda precisa se reinventar. As falas em que esses indivíduos se expressam contra a exclusão do candidato só aparecem no corpo do texto. É o caso de Fernando Haddad em "Com ou sem Lula, a esquerda terá de se repensar"' (GALHARDO, 2018a) e de Olívio Dutra em "Esquerda já devia ter construído alternativas'" (GALHARDO, 2018b).

O segundo contexto comum é o de aliados que não propõem essa autocrítica. São essas opiniões que aparecem em matérias nas quais são empregadas as técnicas de representação descritas acima - de alegações de vitimismo e "explicações" de contexto - ou no material opinativo do jornal, onde são respondidas. É o caso de Gleisi Hoffmann em "Perdendo as estribeiras" (CANTANHÊDE, 2018b), de Guilherme Boulos em "'Movimentos não vão aceitar prisão', declara Boulos" (sem autoria explícita, (Isadora Peron 06/04/18), (PERON, 2018) e de uma série de opinadores aliados em "Lula, 'El-Cid de São Bernardo'” (editorial, 06/04/18) (LULA ..., 2018).

Ao comparar as duas coberturas, notamos que, por si só, a temática de ataque à liberdade de candidatura foi muito mais abordada na cobertura da Venezuela (56\%) do que na do Brasil (6\%). Para além disso, vale observar o enquadramento (ROSSETO; SILVA, 2012) praticado pelo jornal, que enfatiza determinadas temáticas e faz uso das técnicas de representação descritas anteriormente. No caso da Venezuela, o enquadramento do jornal reduz a importância dos processos jurídicos e trata ataques à liberdade de candidatura como elemento intrínseco à eleição venezuelana, o que tende a invalidá-la. No caso do Brasil, a ênfase aos processos jurídicos - que, ademais, são retratados como puramente técnicos - e a reduzida atenção à temática de ataque à liberdade de candidatura - frequentemente negada favorecem a separação de processos jurídicos e eleição, além de afastar a temática

25 That the media provide some facts about an issue, however, proves absolutely nothing about the adequacy or accuracy of that coverage. The mass media do, in fact, literally suppress a great deal, (...) but even more important in this context is the question of the attention given to a fact - its placement, tone, and repetitions, the framework of analysis within which it is presented, and the related facts that accompany it and give it meaning (or preclude understanding). 
de ataque à liberdade de candidatura da eleição brasileira, o que tende a validar o pleito.

Em ambos casos, o espectro de posicionamentos adotados pelos autores do material opinativo foi fortemente direcionado em favor dessas representações. Todos os editoriais sobre o caso da Venezuela foram críticos ao governo ou à eleição em si; igualmente, todos os editoriais sobre o caso do Brasil foram críticos ao candidato excluído. Os artigos de opinião estiveram "fortemente restritos na variedade de opiniões cuja expressão é permitida" (CHOMSKY; HERMAN, 2002, p. 35, tradução nossa $^{26}$ ), jamais discordando das principais premissas do jornal, quais sejam: no caso venezuelano, o autoritarismo do governo; e, no caso brasileiro, a tecnicidade das sentenças condenatórias contra o candidato excluído do pleito.

Vale notar que houve casos de quebra desses padrões, que estiveram intimamente relacionados ao contato direto de jornalistas com opinadores dissidentes. As primeiras matérias produzidas por Rodrigo Cavalheiro na condição de "enviado especial a Caracas" abordam opiniões de diversos atores com distintos posicionamentos, tornando evidente o alinhamento entre as posições do governo e de seu eleitorado, como em "Dormir já rende mais que trabalhar na Venezuela" (CAVALHEIRO, 2018). Similarmente, Ricardo Galhardo foi um dos jornalistas que mais ativamente ouviu vozes dissidentes no cenário brasileiro, produzindo matérias como "Lula diz ao PT que irá ao julgamento no TRF-4" (GALHARDO, 2018c) e "Movimentos montam acampamento e preparam marcha" (GALHARDO, 2018d), em ambos casos sem apelar a técnicas de representação que induzem a interpretações enviesadas. Contudo, em matérias assinadas por Cavalheiro ou Galhardo em conjunto com outros jornalistas, essa quebra de padrões foi diluída. Tais observações sugerem a importância do contato direto com uma diversidade de fontes e a proteção do trabalho autoral do jornalista como ferramentas essenciais de um jornalismo livre e questionador.

Por fim, em relação aos filtros do MP, encontramos indícios da operação do primeiro (propriedade), segundo (publicidade), terceiro (fontes) e quinto (anticomunismo) filtros descritos pelos autores.

O jornal O Estado de São Paulo pertence ao Grupo OESP, ou Grupo Estado, uma corporação midiática de propriedade privada da família Mesquita. Além do jornal, o Grupo possui empreendimentos em outros setores midiáticos e em áreas diversas como educação e análise de dados (MEDIA OWNERSHIP MONITOR BRASIL, 2016). O filtro de propriedade indica que tais conexões estimulam o jornal a adotar posicionamentos pró-mercado. Há indícios desse filtro na cobertura do caso do Brasil, dada a ênfase às reações do mercado sobre o tema. A visão do mercado sobre a exclusão do candidato do pleito brasileiro em função de processos jurídicos é melhor resumida no artigo de opinião "Três a zero ou zebra" (ALVES, 2018): "com um placar de 3 a 0 no julgamento do TRF-4 contra Lula, é provável que a Bolsa, o real e outros ativos brasileiros sigam tendo desempenho acima dos seus pares emergentes"; já "uma decisão contra Lula, mas com placar dividido, deixará os ativos brasileiros com desempenho em linha com os de outros países emergentes". E, por fim, "se Lula for absolvido pelo TRF-4? 'Aí vai ser um Deus nos acuda'”.

O filtro de publicidade trata da pressão sobre as mídias para cativar uma audiência de "qualidade", ou seja, "uma audiência com poder de compra, não uma audiência per se" (CHOMSKY; HERMAN, 2002, p. 16, tradução nossa ${ }^{27}$ ). É esse tipo

26 In the opinion columns, we would anticipate sharp restraints on the range of opinion allowed expression.

${ }^{27}$ The mass media are interested in attracting audiences with buying power, not audiences per se. 
de audiência, afinal, que "desperta o interesse de anunciantes" (ibidem ${ }^{28}$ ). O resultado é que "uma tal imprensa está fadada a respeitar o ponto de vista do público comprador" (LIPPMANN, 2020, p. 175, tradução nossa ${ }^{29}$ ). É possível encontrar indícios do que pensa a audiência que o jornal busca cativar em seu "Fórum dos Leitores", ao menos em relação ao caso do Brasil. Como observamos, $96 \%$ dos comentários expressos ali eram críticos ao candidato excluído do pleito.

O filtro de fontes foi especialmente significativo na cobertura da eleição venezuelana. Há indícios de dependência do jornal de centros de poder globais para obter informações sobre o exterior. Cerca de $65 \%$ do material do jornal sobre a questão era de autoria de jornais e agências internacionais de notícias ligados a EUA e UE, ou de correspondentes internacionais estabelecidos nesses lugares. São essas matérias - em especial aquelas assinadas por agências internacionais - as que mais fazem uso das "técnicas" de representação descritas por Sierra Caballero (2018). A possibilidade de que o material fornecido por fontes ligadas a essas potências - que são opositoras à Venezuela no cenário internacional - fosse enviesado contra o governo venezuelano não parece ser levada em conta.

Por fim, também há amplos indícios do filtro de anticomunismo, em especial no material opinativo do jornal. Em "O dia de ira" (ROSENFIELD, 2018), afirma-se que os "movimentos que orbitam em torno do partido [PT]" têm um "explícito programa revolucionário em moldes marxistas, voltado para a destruição da economia de mercado, da propriedade privada e do Estado de Direito"; a própria Venezuela é usada para disciplinar a esquerda brasileira: "o PT, aliás, não cessa de defender o 'socialismo do século 21', o bolivarianismo, Chávez, Maduro e asseclas. É isso que querem para - Brasil!". Já em "A persistente e cansativa cara de pau de Lula e do PT" (RODRÍGUEZ, 2018), Lula é acusado de adotar estratégias políticas usadas "pelos totalitários desde os jacobinos e Lenin até os dias atuais". Mais indícios de anticomunismo podem ser encontrados em "Perdendo as estribeiras" (CANTANHÊDE, 2018b), "O drama é maior do que 2018" (AGGIO, 2018), "A velha "nova esquerda"” (FAUSTO, 2018) e "Você sabe quem está prendendo?" (DAMATTA, 2018), dentre muitos outros.

\section{CONCLUSÃO}

O MP ainda é bastante desconhecido nos estudos de comunicação, o que leva à sua marginalização e a críticas superficiais acerca de sua aplicabilidade, como o próprio Noam Chomsky nota (MACLEOD, 2019, p. 12). Frequentemente tratado como teoria da conspiração, reiteramos que o MP na verdade é, antes de tudo, uma crítica institucional fundamentada em uma "análise de 'livre mercado', cujos resultados são em grande parte decorrentes da ação de forças de mercado" (CHOMSKY; HERMAN, 2002, p. LX, tradução nossa ${ }^{30}$ ).

O propósito desta pesquisa foi empregar o MP no estudo do comportamento das mídias brasileiras a fim de testar sua aplicabilidade no Brasil. Observamos ao longo deste estudo que as condições institucionais e econômicas das mídias brasileiras de fato são adequadas para o emprego desse tipo de pesquisa. Mesmo em tempos de hegemonia do modelo digital de comunicação, as chamadas "mídias tradicionais" como o impresso - continuam submetidas às pressões descritas pelo MP. O comportamento da mídia estudada refletiu amplamente as previsões do modelo, tendo

\footnotetext{
28 It is affluent audiences that spark advertiser interest today.

${ }^{29}$ Such a press is bound to respect the point of view of the buying public.

${ }^{30} \mathrm{~A}$ 'free market' analysis, with the results largely an outcome of the workings of market forces.
} 
sido demonstrada a aplicabilidade dos filtros de propriedade, publicidade, fontes e anticomunismo no cenário midiático brasileiro.

Em relação ao tema estudado - a cobertura da exclusão de candidatos por processos jurídicos nas eleições presidenciais brasileira e venezuelana de 2018 concluímos que nossas proposições foram verificadas.

Em sua cobertura da eleição venezuelana, o jornal sistematicamente corroborou alegações de ataque à liberdade de candidatura, representando o pleito como inválido. De fato, a representação feita pelo veículo foi mais radical do que esperávamos neste caso, visto que os processos jurídicos contra os candidatos receberam atenção reduzida e a temática de ataque à liberdade de candidatura foi retratada como um a priori da eleição venezuelana.

$\mathrm{Na}$ cobertura da eleição brasileira, por outro lado, o jornal rechaçou alegações de ataque à liberdade de candidatura, representando o pleito como válido. Essas alegações não só receberam atenção reduzida, como foram sistematicamente negadas. Ademais, os processos jurídicos contra o candidato excluído foram amplamente retratados como técnicos e imparciais, e distanciados da interpretação de que teriam natureza política.

Contudo, também observamos instâncias de quebra desses padrões de cobertura em momentos nos quais princípios fundamentais do jornalismo - como o contato direto com fontes dissidentes e a proteção do trabalho autoral dos jornalistas - foram utilizados por profissionais que se valeram de brechas no sistema para apresentar, sem distorções, visões alternativas à cobertura hegemônica.

Consideramos essencial destacar esse achado por entender que compete ao trabalho científico e acadêmico buscar nas instituições midiáticas as instâncias de subversão dos paradigmas desse sistema. Afinal, é nesses momentos que se evidenciam as ferramentas que podem ser usadas para construir um jornalismo questionador e independente, que efetivamente cumpra sua função, escapando das restrições profundamente imbuídas nas mídias pelas dinâmicas de poder típicas de sociedades capitalistas.

\section{REFERÊNCIAS}

AGGIO, A. O drama é maior do que 2018. O Estado de S. Paulo, São Paulo, 07 mar. 2018. Disponível em: https://opiniao.estadao.com.br/noticias/geral,o-drama-emaior-do-que-2018,70002216655. Acesso em: 19 out. 2021.

ALVES, F. Três a zero ou zebra. O Estado de S. Paulo, São Paulo, 24 jan. 2018. Disponível em: https://economia.estadao.com.br/noticias/geral,tres-a-zero-ouzebra,70002162693. Acesso em: 19 out. 2021.

BOURDIEU, P. O poder simbólico; tradução de Fernando Tomaz. Rio de Janeiro: Bertrand Brasil, 1989.

BRASIL. MINISTÉRIO DAS RELAÇÕES EXTERIORES. Nota à imprensa n 1/2019: Declaração do Grupo de Lima. Brasília, DF, 4 jan. 2019. Disponível em: https://www.gov.br/mre/pt-br/canais atendimento/imprensa/notas-aimprensa/2019/declaracao-do-grupo-de-lima-4. Acesso em: 28 jun. 2021. 
CANTANHÊDE, E. Injustas e ilegítimas. O Estado de S. Paulo, São Paulo, 22 mai. 2018a. Disponível em: https://politica.estadao.com.br/noticias/geral,injustas-eilegitimas,70002318497. Acesso em: 19 out. 2021.

CANTANHÊDE, E. Perdendo as estribeiras. O Estado de S. Paulo, São Paulo, 19 jan. 2018b. Disponível em: https://politica.estadao.com.br/noticias/geral,perdendoas-estribeiras, 70002156613 . Acesso em: 19 out. 2021.

CAVALHEIRO, R. Crise na Venezuela faz com que dormir renda mais que trabalhar. O Estado de S. Paulo, São Paulo, 18 mai. 2018. Disponível em:

https://internacional.estadao.com.br/noticias/geral,crise-na-venezuela-faz-com-quedormir-renda-mais-que-trabalhar,70002313369. Acesso em: 19 out. 2021.

CHAVISMO antecipa para até abril as eleições presidenciais na Venezuela. $\mathbf{O}$

Estado de S. Paulo, São Paulo, 23 jan. 2018. Disponível em:

https://internacional.estadao.com.br/noticias/geral,chavismo-antecipa-para-ate-abrileleicoes-presidenciais-na-venezuela,70002162047. Acesso em: 19 out. 2021.

CHOMSKY, N. Mídia: Propaganda política e manipulação; tradução de Fernando Santos. São Paulo: WMF Martins Fontes, 2013.

CHOMSKY, N.; HERMAN, E. S. Manufacturing Consent: The Political Economy of the Mass Media. $2^{a}$ edição. Nova York: Pantheon Books, 2002.

CONSELHO DA UE. Declaration by the High Representative on behalf of the EU on the presidential and regional elections in Venezuela. Bruxelas: Assessoria de imprensa do Secretariado-Geral do Conselho da União Europeia, 22 maio 2018.

Disponível em: https://www.consilium.europa.eu/en/press/press-

releases/2018/05/22/declaration-by-the-high-representative-on-behalf-of-the-eu-onthe-presidential-and-regional-elections-in-venezuela/pdf. Acesso em: 28 jun. 2021.

CORSI, F. L.; SANTOS, A.; CAMARGO, J. M. AAmérica latina: Ciclo de commodities e a crise do capitalismo global. Austral: Revista Brasileira de Estratégia e Relações Internacionais, Porto Alegre, v. 8, n. 15, p. 168-194, jan./jun. 2019. DOI: https://doi.org/10.22456/2238-6912.89388

DAMATTA, R. Você sabe quem está prendendo? O Estado de S. Paulo, São Paulo, 11 abr. 2018. Disponível em: https://cultura.estadao.com.br/noticias/geral,voce-sabequem-esta-prendendo,70002263043. Acesso em: 19 out. 2021.

ESTADÃO. Perseguição de Maduro dificulta campanha de rivais. O Estado de S.Paulo, São Paulo, 24 jan. 2018. Editoria Internacional. Disponível em: https://internacional.estadao.com.br/noticias/geral,perseguicao-de-maduro-dificultacampanha-de-rivais,70002164354. Acesso em: 27 fev. 2021.

FAUSTO, S. A velha 'nova esquerda' O Estado de S.Paulo, São Paulo, 23 mar. 2018. Disponível em: https://opiniao.estadao.com.br/noticias/geral,a-velha-novaesquerda,70002238803. Acesso em: 27 fev. 2021.

GALHARDO, R. 'Com ou sem Lula, a esquerda terá de se repensar', diz Haddad. 0 Estado de S. Paulo, São Paulo, 21 jan. 2018a. Disponível em: 
https://politica.estadao.com.br/noticias/geral,com-ou-sem-lula-a-esquerda-tera-de-serepensar-diz-haddad,70002158933. Acesso em: 19 out. 2021.

GALHARDO, R. Para Olívio Dutra, PT já deveria 'estar construindo alternativas' a Lula. O Estado de S. Paulo, São Paulo, 22 jan. 2018b. Disponível em:

https://politica.estadao.com.br/noticias/geral,para-olivio-dutra-pt-ja-deveria-estarconstruindo-alternativas-a-lula,70002160356. Acesso em: 19 out. 2021.

GALHARDO, R. À espera do julgamento de Lula, movimentos montam acampamento em Porto Alegre. O Estado de S. Paulo, São Paulo, 21 jan. 2018d. Disponível em: https://politica.estadao.com.br/noticias/geral,a-espera-do-julgamentode-lula-movimentos-montam-acampamento-em-porto-alegre, 70002159603 . Acesso em: 19 out. 2021.

GALHARDO, R. Lula diz ao PT que irá ao julgamento no TRF-4. O Estado de S. Paulo, São Paulo, 03 jan. 2018c. Disponível em:

https://politica.estadao.com.br/noticias/geral,lula-diz-ao-pt-que-ira-ao-julgamento-notrf-4,70002136662. Acesso em: 19 out. 2021.

HALL, S. Representation \& The Media. Northampton: Media Education Foundation, 1997. Disponível em: <https://www.mediaed.org/transcripts/Stuart-Hall-

Representation-and-the-Media-Transcript.pdf>. Acesso em: 26 dez 2020.

HERMAN, E. S. Triumph of the Market: essays on economics, politics, and the media. Montreal: Black Rose Books, 1997.

HIROSE, R. Folha e O Globo reivindicam título de maior jornal do Brasil. Jornal Opção, Goiânia, 26 jan. 2020. Disponível em:

https://www.jornalopcao.com.br/colunas-e-blogs/imprensa/folha-e-o-globoreivindicam-titulo-de-maior-jornal-do-brasil-232520/. Acesso em: 23 fev. 2021.

HOLANDA, M; KATTAH, E. 'Geraldo é um corredor de maratona', diz Fernando Henrique. O Estado de S. Paulo, São Paulo, 20 abr. 2018. Disponível em: https://politica.estadao.com.br/noticias/eleicoes,geraldo-e-um-corredor-demaratona,70002276174. Acesso em: 19 out. 2021.

IBOPE - Instituto Brasileiro de Opinião Pública e Estatística. Lula fica à frente na disputa pela Presidência da República. No cenário com Haddad como opção do PT, Bolsonaro aparece na liderança. Ibope inteligência, 2018. Disponível em:

https://www.ibopeinteligencia.com/noticias-e-pesquisas/lula-fica-a-frente-na-disputapela-presidencia-da-republica-no-cenario-com-haddad-como-opcao-do-pt-bolsonaroaparece-na-lideranca/. Acesso em: 15 jan. 2021.

LASSWELL, H. D. The Theory of Political Propaganda. The American Political Science Review, v. 21, n. 3, p. 627-631, 1927. Disponível em: www.jstor.org/stable/1945515. Acesso em: 26 dez. 2020.

LIPPMANN, W. Public opinion. [S.I.]: Digireads, 2020.

LULA, ‘El Cid de São Bernardo’. O Estado de S. Paulo, São Paulo, 06 abr. 2018. 
Disponível em: https://opiniao.estadao.com.br/noticias/geral,lula-el-cid-de-saobernardo,70002256664. Acesso em: 19 out. 2021.

MACLEOD, A. Manufacturing Consent for the 2018 Elections in Venezuela and Colombia. Media Theory, Media Theory, v. 2, n. 2 spe., p. 138-153, 2018. hal02047706. Disponível em: https://hal.archives-ouvertes.fr/hal-02047706/document. Acesso em: 15 jan. 2021.

MACLEOD, A. Propaganda in the Information Age: Still Manufacturing Consent. Abingdon: Routledge, 2019.

MAGALHÃES, V. O julgamento estritamente técnico enfraquece a tese do PT. O Estado de S.Paulo, São Paulo, 24 jan. 2018a. Disponível em:

https://politica.estadao.com.br/noticias/geral,julgamento-estritamente-tecnicoenfraquece-tese-do-pt,70002164300. Acesso em: 18 out. 2021.

MAGALHÃES, V. Que as instituições falem. O Estado de São Paulo, São Paulo, 8 abr. 2018b. Disponível em: https://politica.estadao.com.br/noticias/geral,que-asinstituicoes-falem,70002259249. Acesso em:18 out. 2021.

MEDIA OWNERSHIP MONITOR BRASIL. Grupo OESP (Estado). 2016. Disponível em: https://brazil.mom-

rsf.org/br/proprietarios/empresas/detail/company/company/show/grupo-oesp-estado/. Acesso em: 23 mar. 2021.

PERON, I. Movimentos sociais não vão assistir à prisão de Lula passivamente, diz Boulos. O Estado de S. Paulo, São Paulo, 05 abr. 2018. Disponível em:

https://politica.estadao.com.br/noticias/geral,movimentos-sociais-nao-vao-assistir-aprisao-de-lula-passivamente-diz-boulos,70002256460. Acesso em: 19 out. 2021.

PT. Diretório Nacional do Partido dos Trabalhadores. Nota do PT: Julgamento no TSE é mais uma discriminação contra Lula. Notícias PT, 31 ago. 2018. Disponível em: https://pt.org.br/nota-do-pt-julgamento-no-tse-e-mais-uma-discriminacao-contralula/. Acesso em: 15 jan. 2021.

RODRÍGUEZ, R. V. A persistente e cansativa cara de pau de Lula e PT. O Estado de S. Paulo, São Paulo, 17 jan. 2018. Disponível em:

https://opiniao.estadao.com.br/noticias/geral,a-persistente-e-cansativa-cara-de-paude-lula-e-pt,70002153534. Acesso em: 19 out. 2021.

ROSA, V. O PT teme encolher se lula for barrado na eleição. O Estado de S.Paulo, São Paulo, 21 jan. 2018. Disponível em:

https://politica.estadao.com.br/noticias/geral,pt-teme-encolher-se-lula-for-barrado-naeleicao,70002158860. Acesso em: 18 out. 2021.

ROSENFIELD, D. L. O dia da ira. O Estado de S. Paulo, São Paulo, 08 jan. 2018.

Disponível em: https://opiniao.estadao.com.br/noticias/geral,o-dia-da-

ira,70002141953. Acesso em: 19 out. 2021.

ROSSETO, G. P. N.; SILVA, A. M. Agenda-setting e framing: detalhes de uma 
mesma teoria? Intexto, Porto Alegre, n. 26, p. 98-114, jul. 2012.

SIERRA CABALLERO, F. Imperialism and Hegemonic Information in Latin America: The Media Coup in Venezuela vs. The Criminalization of Protest in Mexico. In: PEDRO-CARAÑANA, J; BROUDY, D; KLAEHN, J. (eds.). The Propaganda Model Today: Filtering Perception and Awareness. London: University of Westminster Press, 2018. p. 237-248. DOI: https://doi.org/10.16997/book27.

SIMULACRO de democracia. O Estado de S. Paulo, São Paulo, 22 mai. 2018. Disponível em: https://opiniao.estadao.com.br/noticias/geral,simulacro-dedemocracia,70002318404. Acesso em: 19 out. 2021.

TREVISAN, C; CAVALHEIRO, R; OTA, L. A. EUA ampliam sanções à Venezuela e bloco regional critica eleição de Maduro. O Estado de S. Paulo, São Paulo, 22 mai. 2018. Disponível em: https://internacional.estadao.com.br/noticias/geral,euaampliam-sancoes-a-venezuela-e-bloco-regional-critica-eleicao-demaduro,70002318372. Acesso em: 19 out. 2021. 